\title{
Bleach (sodium hypochlorite): a laboratory experiment relating to the daily teaching of chemistry
}

\author{
Fernando B. Mainier*, Luciane P. C. Monteiro*, Renata Jogaib Mainier** \\ *Escola de Engenharia, Universidade Federal Fluminense, Niterói, RJ, Brazil \\ **Universidade Salgado de Oliveira, Niterói, RJ, Brazil
}

\begin{abstract}
This work is part of a group of laboratory experiments whose aim is to establish relations between everyday life and the teaching of chemistry by showing that knowledge of chemistry is not abstract, and is closely related to its surroundings. A bleach-solution with about $2 \%$ (by mass) sodium hypochlorite (NaClO) was the theme chosen in view of its widely varied uses since its introduction for laundering and disinfection of clothing. The experiment consists of four phases: a) the evaluation of various kinds of commercial bleach; $b$ ) preparation of bleach in the laboratory from generated chlorine and bubbling it through a sodium hydroxide solution. At this stage two chlorine generator experiments are constructed; the first from the reaction between hydrochloric acid and manganese dioxide $\left(\mathrm{MnO}_{2}\right)$ and the second through the electrolysis of sodium chloride solution. The chlorine gas $\left(\mathrm{Cl}_{2}\right)$ is bubbled in a solution of sodium hydroxide $(\mathrm{NaOH})$ to produce bleach; c) preparation for the quantitative analysis of the levels of hypochlorite in commercial bleach; d) evaluation of the chemical properties of sodium hypochlorite solutions. The objective is to enable students to develop their skills in the development of the theme "chemical process" based on the following points: teamwork; analysis and evaluation of information from observations; decision making from a restricted amount of information; querying technical bibliographies; making technical reports and oral presentations.
\end{abstract}

Keywords: Bleach, Sodium Hypochlorite, Laboratory Experiments, Teaching of Chemistry.

\section{INTRODUCTION}

From the point of view of scientific research, since Antiquity, the use of experimentation has always been a striking trait of the natural sciences. It is observed that scientists, most of the time, produce and reproduce phenomena under artificial conditions, with phenomenological controlled and/or selected variables aiming to shed light on a significant issue $[1,2,3]$.

Chalmers [4] emphasizes that some general aspects of experimental research may have settings where the experimental results are inappropriate and will not be a secure basis for the unveiling of a matter. However, it should be clear that the results are fruits of how the world works regardless of the results obtained on the basis of the personal point of view of any browser. This means that the results should not be manipulated to misrepresent the matter.

Chalmers [4] still, explains that experimental results are always under constant challenges. Therefore they should be constantly reviewed, revised, rethought, considered irrelevant or even rejected; thereby, the experimental basis of science is constantly updated and transformed and has nothing to do with a particular observer or human perception. In this way, experiments must be constructed in order to obtain meaningful data, whether quantitative or qualitative.

It is not objective of this study to evaluate critically whether controversies in science can be resolved through experiments conducted in a scientific and objective manner, because the results from any experiments can either lead to satisfactory resolutions or not.

The critical evaluation is whether the experimental models intended for the teaching of chemistry for Engineering Courses proposed in this work will be able to develop in students the knowledge necessary to understand the principles, laws, methods and techniques relating to chemistry and its interaction with the environment.

Educational experiments can be classified into two different aspects. The first can be developed to serve as a reference base and solidify logical reconstruction activities through the use of symbolic codes. The second type of experiment is subordinate to the interests of the researcher aimed at elucidating questions and seeking answers through private investigation. In order to achieve the objectives of the teaching of chemistry, you can either allow the engineering student to discover knowledge on their own motivated by curiosity or to learn by performing a carefully oriented and planned experiment.

The purpose of this work, in accordance with the basic ideas of Giordan \& Vecchi [5], is the development of a learning process based on the construction of teaching models, using specific equipment or even certain everyday objects in order to create the necessary conditions and fundamental experiments to convey that knowledge of applied chemistry is, at the same time, both critical and systemic. 
Thus, modifications or transformations that occur during the experiments should generate "signs", indications, as for example, colour changes or the appearance of odours (well-defined characteristics of some chemical reactions) that can magically involve students in critical experimentation, in search of this "feeling" [6].

The colour changes observed in a chemical reaction during a trial can be characterized as a visual image. However, this is far from being a perfect replica of the retinal image and even further from being a transparent and faithful copy of the actual object that is currently being seen [7].

However, the stimuli that impress the retina become a mosaic of points, in turn transmitted to the brain by a complex of optical nerve cells that then integrate with the neuronal connections from other senses and sensory experience precedents, prior to coalescing into conscious imagery that will be part of the real world, with colour, shape, dimensions, spatial perspective, sound etc. Perceptions are not therefore mere reflections of things. Each new perception and each new learning experience do so in a logical sequence in the context of learning schemes built in succession [2].

In the development of this learning process, aiming at a progressive interpretation of neural events, there is the need to develop a series of parameters such as: active and progressive search, selection, operation and integration of new experiences. All of these factors aim to build the conscious mind, which relates to critical visual information, a fundamental item in the process of interaction and interrelationships between chemistry and the everyday $[8,9]$.

Bleach (a solution with about $2 \%$ sodium hypochlorite), for example, was the chosen theme from everyday life with a view to its varied uses, its best known being its use in disinfecting clothing.

From an environmental and technological point of view it is important to emphasize to students who participate in this experiment that bleach, a product they use in their daily lives, is associated with the chlorinecaustic soda industry, remembering that this industrial complex has investments of more than six billion dollars. The chlor-alkali industry produces chlorine, hydrogen and sodium hydroxide (caustic soda) from concentrated solutions $(300 \mathrm{~g} / \mathrm{L})$ of sodium chloride using three routes: electrolyte cells made of mercury, diaphragms and membranes.

A method of producing sodium hydroxide based on mercury cells was discovered in 1892; however, the process only became commercially practical from 1940 onward. Currently, due to problems with pollution, the use of mercury cells has been discontinued throughout the world, although they still represent $5 \%$ of global production because they produce a high purity caustic soda $[10,11,12,13]$.

In Brazil and various other parts of the world there are still plants that use mercury electrolytic cells. It is therefore valid to inform students of the possible existence of bleach contaminated with traces of mercury, which can potentially contaminate the environment and consequently the human population. In general, mercury losses are associated with the processing, cleaning and maintenance of the cells. It is estimated that $200 \mathrm{~g}$ of mercury are consumed per ton of sodium hydroxide produced.

The diaphragm cell technology developed in the 1960s accounts, currently, for about $70 \%$ of world production, producing a caustic soda containing about $0.1 \%$ sodium chloride. At the same time the newer membrane cell technology is making advances on the world stage because it produces sodium hydroxide with the same purity as mercury cells without causing environmental impacts $[13,14,15]$.

\section{BASIC PRINCIPLES OF THE EXPERIMENTS}

Based on the experience of the authors, the various phases of experiments that are proposed should comply with the following principles and general procedures:

- The demonstrations should be supported by experiments that have great pedagogical value, allowing students have direct contact with applied chemistry.

- The practical work must be carried out either individually or in small groups.

- The theoretical principles established should be illustrated and explained;

- It is essential to seek to awaken in students the need to develop and clarify the physico-chemical mechanisms that are involved in each stage of the experiment.

- It is important to orient students towards research and critical thinking, giving them basic experience in the kinds of physical and chemical measurements that lead to qualitative and quantitative results while always seeking to establish their relationships with applied chemistry.

- Stimulate the persistent search for technological innovation through special projects and, if necessary, to break from the course of traditional experiments.

- Seek to establish simplicity as a goal in the development of laboratory experiments. 


\section{DESCRIPTION OF THE EXPERIMENTS}

\subsection{Evaluation of various trademarks of commercial bleach}

At this stage various trademarks of bleach found in supermarkets are presented on the basis of the following parameters:

- $\quad$ specification of label

- manufacturer

- volume

- chlorine content

- price.

For example, based on the Brazilian market we acquired eight commercial bleach samples where black bars were placed over the labels so as not to make comparisons between the brands tested. The eight brands of bleach are shown in Figure 1.

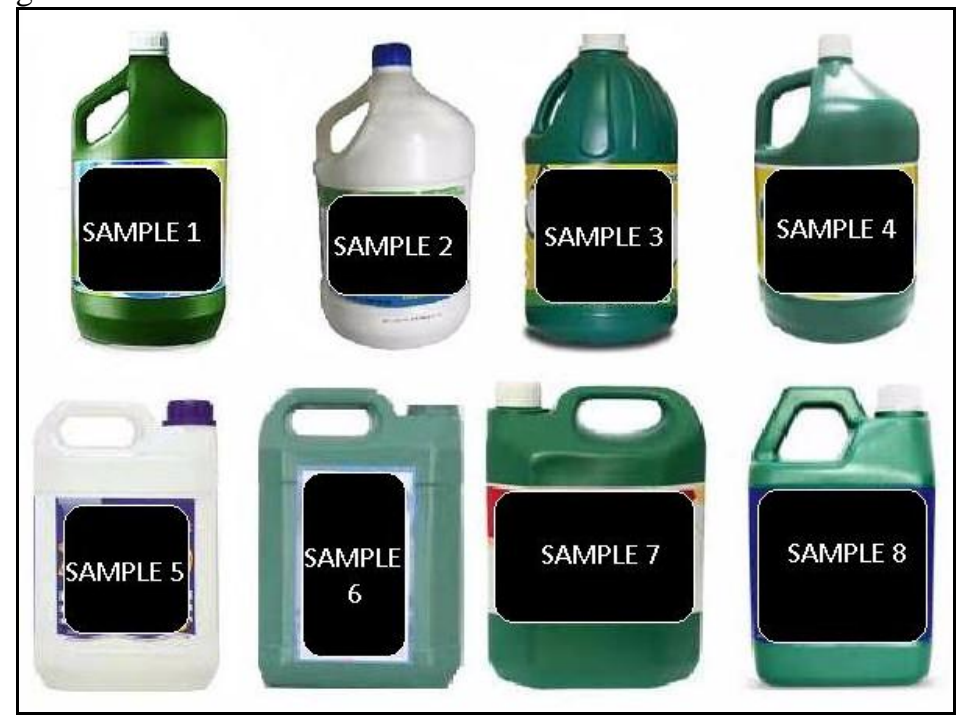

Figure 1 - View of eight containers of bleach

\subsection{Preparation of sodium hypochlorite (bleach) in the laboratory}

The objective of this phase is to prepare sodium hypochlorite (bleach) in the laboratory through the bubbling of chlorine $\left(\mathrm{Cl}_{2}\right)$ in sodium hydroxide $(\mathrm{NaOH})$ solution as shown in the following reaction:

$$
\mathrm{Cl}_{2}+2 \mathrm{NaOH} \rightarrow \mathrm{NaClO}+\mathrm{NaCl}+\mathrm{H}_{2} \mathrm{O}
$$

\subsection{Production of chlorine from the reaction of manganese dioxide and hydrochloric acid}

As shown in the illustration in Figure 2, the chlorine gas $\left(\mathrm{Cl}_{2}\right)$ is generated by placing approximately $20 \mathrm{~g}$ of manganese dioxide $\left(\mathrm{MnO}_{2}\right)$ in an Erlenmeyer flask on a hotplate, when $120 \mathrm{~mL}$ of concentrated hydrochloric acid are added slowly through a funnel as represented by the equation:

$\mathrm{MnO}_{2}+4 \mathrm{HCl} \rightarrow \mathrm{MnCl}_{2}+\mathrm{Cl}_{2}+2 \mathrm{H}_{2} \mathrm{O}$

With heating, the chlorine gas flows from the flask to a beaker containing $500 \mathrm{~mL}$ of $1 \%$ (by mass) sodium hydroxide solution to form sodium hypochlorite (bleach).

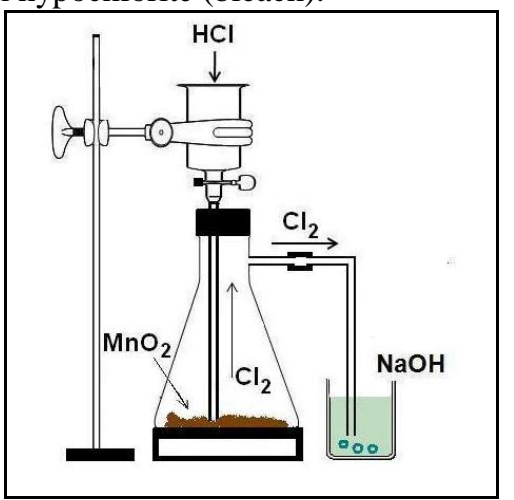

Figure 2 - Laboratory scheme showing chlorine generation and sodium hypochlorite 


\subsection{Production of chlorine from the electrolysis of a sodium chloride solution}

Chlorine $\left(\mathrm{Cl}_{2}\right)$ is produced in the laboratory by means of an electrolytic cell as presented in Figure 3. The electrolytic cell consists, essentially, of two electrodes (anode and cathode) inserted into two glass tubes with outputs for the outflow, respectively, of chlorine $\left(\mathrm{Cl}_{2}\right)$ and hydrogen $\left(\mathrm{H}_{2}\right)$, whose electrochemical reactions are presented below:

Anodic reaction: $2 \mathrm{Cl}^{-}-2 \mathrm{e}^{-} \rightarrow \mathrm{Cl}_{2}$

Cathodic reaction: $2 \mathrm{H}_{2} \mathrm{O}+2 \mathrm{e}^{-} \rightarrow \mathrm{H}_{2}+2 \mathrm{OH}^{-}$

The electrolytic cell is placed in a solution of $300 \mathrm{~g} / \mathrm{L}$ sodium chloride and then an electrical current is applied using a direct current source. Chlorine given off at the graphite anode is bubbled through a beaker containing a $1 \%$ sodium hydroxide solution to form chlorine bleach.

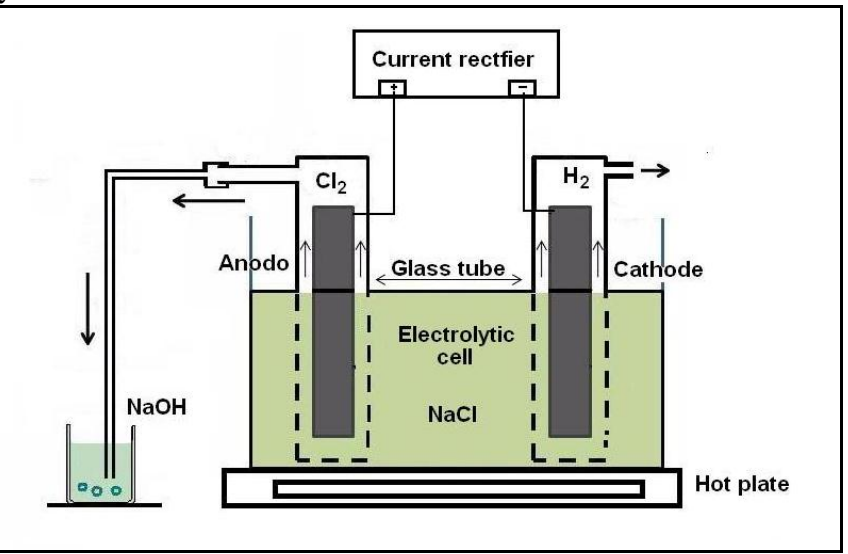

Figure 3 - Electrolytic Cell scheme showing chlorine generation and sodium hypochlorite

\subsection{Quantitative determination of chlorine content in commercial bleach}

The determination of chlorine is based on the ionic dissociation of the hypochlorite ion $\left(\mathrm{ClO}^{-}\right)$in an acid medium forming chlorine according to the reaction:

$\mathrm{ClO}^{-}+2 \mathrm{H}^{+}+\mathrm{Cl}^{-} \rightarrow \mathrm{Cl}_{2}+\mathrm{H}_{2} \mathrm{O}$

The free chlorine formed in the reaction is determined by iodometry that consists of the addition of potassium iodide (KI) and sulphuric acid to the sample of bleach according to the reaction:

$\mathrm{ClO}^{-}+2 \mathrm{I}^{-}+2 \mathrm{H}^{+} \rightarrow \mathrm{Cl}^{-}+\mathrm{I}_{2}+\mathrm{H}_{2} \mathrm{O}$

The amount of iodine released is equivalent to chlorine free and can be titrated with a standard sodium thiosulphate solution $0.1 \mathrm{~N}$ according to the reaction:

$2 \mathrm{~S}_{2} \mathrm{O}_{3}^{-2}+\mathrm{I}_{2} \rightarrow \mathrm{S}_{4} \mathrm{O}_{6}^{-2}+2 \mathrm{I}^{-}$ (Figure 4):

The following are the steps necessary for determination of chlorine present in each commercial bleach

- Step 1 - First, the dilution is made of a sample of commercial bleach, as follows: $10 \mathrm{~mL}$ of "bleach" is transferred to a $100 \mathrm{~mL}$ volumetric flask and the remaining volume is completed with distilled water.

- Step 2 - Through a pipette, take an aliquot of $10 \mathrm{~mL}$ of the diluted solution (volumetric flask of $100 \mathrm{ml}$ ) to be analysed and transferred to an Erlenmeyer flask.

- Step 3 - Add to the Erlenmeyer flask $10 \mathrm{~mL}$ of sulphuric acid solution $10 \%$ (by mass), $10 \mathrm{~mL}$ of potassium iodide $20 \%$ (by mass) and $5 \mathrm{~mL}$ of distilled water.

- Step 4 - dropping the sodium thiosulphate solution through burette until the specimen becomes light yellow; Add $5 \mathrm{~mL}$ of starch solution and continue to drip out the blue coloration; write down the amount spent and repeat the titration.

Calculate the content of free chlorine in "bleach" based on the following equation:

$$
\% \mathrm{Cl}_{2}=\frac{V_{1} N_{1} m e q \mathrm{Cl}_{2} \times 100}{V_{\text {aliq }} V_{\text {dil }}}
$$

Where:

$\mathrm{V}_{1}=\mathrm{Na}_{2} \mathrm{~S}_{2} \mathrm{O}_{3}$ volume required in the titration

$\mathrm{N}_{1}=$ normality of the solution of $\mathrm{Na}_{2} \mathrm{~S}_{2} \mathrm{O}_{3}$ meqCl $_{2}=$ milliequivalents-gram $=35.5 \times 10^{-3}$

$\mathrm{V}_{\text {aliq }}=$ volume of the aliquot for dilution used in titration

$\mathrm{V}_{\mathrm{dil}}=$ final solution dilution volume after dilution 


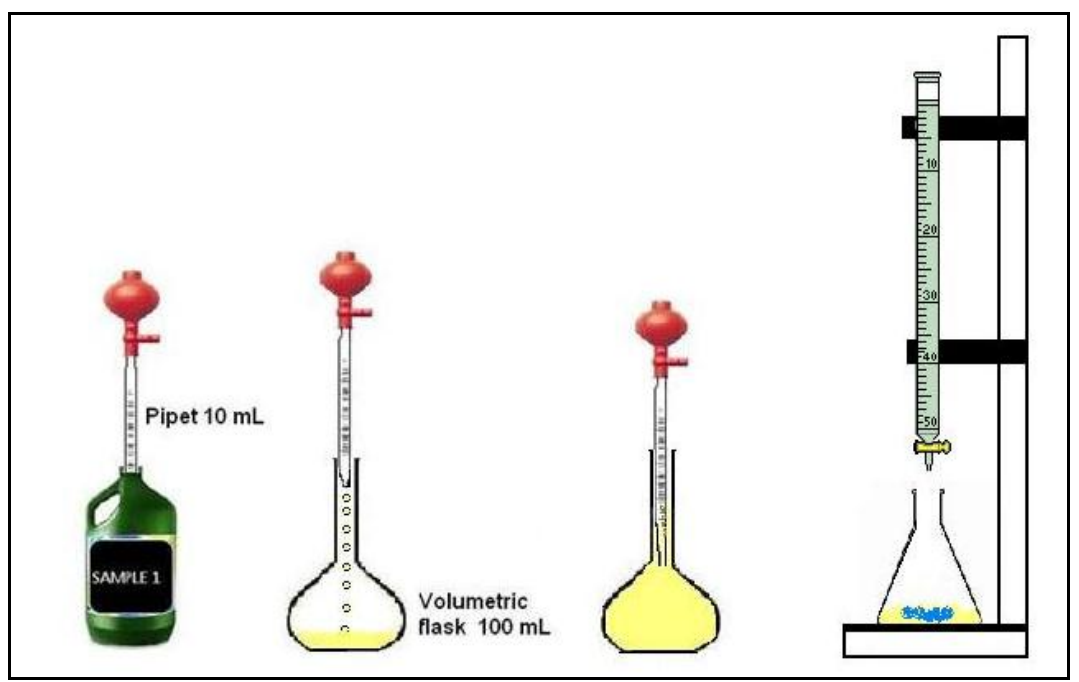

Figure 4 - Determination of chlorine present in each commercial bleach

\subsection{Preparation of the report}

In this final step, students must prepare a report that contains a description of the experiments, the reactions involved, the results, observations, a critical analysis of the experiment and the final conclusions.

\subsection{Safety in the laboratory}

It is important to note that all safety standards must be met so that the experiments are performed in the chapel with exhaustion and students should wear personal protective equipment such as safety glasses, clothing suitable for the laboratory, gloves, etc. In addition, it is important to emphasize the use of pipettes with suction devices as shown in Figure 4.

\section{CONCLUSIONS}

Based on the experiences of the authors in the context of the classwork performed by students in the chemistry lab, we can conclude that the experiment with bleach makes a bridge connection between the everyday world and the teaching of chemical properties and chemical reactions.

\section{REFERENCES}

[1] P. C. C. Abrantes, Imagens de natura, imagens de ciência (São Paulo, Brazil: Papirus, 1998).

[2] H. D. Barke, A. Hazari \& S. Yitbarek, Misconceptions in chemistry: Addressing perceptions in chemical education (Springer, 2009).

[3] H. J. So \& B. Kim, Learning about problem based learning: Student teachers integrating technology, pedagogy and content knowledge, Australasian Journal of Educational Technology, 25(1), 2009, 101-116.

[4] A. Chalmers, A fabricação da ciência (São Paulo; Brazil: Editora da Universidade Estadual Paulista, 1994).

[5] A. Giordan \& G. Vecchi, Les origines du savoir des conceptions des apprenants aux concepts scientifiques (Paris: Delachaux et Niestlé, 1994).

[6] F. B. Mainier, L. P. C. Monteiro, F. Merçon, P. I. C. Guimarães and R. J. Mainier, Teaching of corrosion based on critical evaluation of urban furniture of a public square, Journal of Research \& Method in Education, Volume 3, Issue 3 (Sep.-Oct), 2013, 13-19.

[7] A. L. Chandrasegaran, D. F. Treagust and M. Mocerino, M., An evaluation of a teaching intervention to promote students' ability to use multiple levels of representation when describing and explaining chemical reactions. Research in Science Education, 38.2, $2008,237-248$

[8] J. K. Gilbert \& D. F. Treagust, Introduction: Macro, submicro and symbolic representations and the relationship between them: Key models in chemical education. Multiple representations in chemical education. Springer Netherlands, 2009, 1-8.

[9] F. B. Mainier, L. P. C. Monteiro, A. C. M. Rocha and R. J. Mainier, Industrial electrochemical: a new teaching approach, American Journal of Engineering Research, Volume-02, Issue-08, 2013, 58-64,

[10] M. B. Hocking, Handbook of chemical technology and pollution control (Academic Press, 2006).

[11] J. Moorhouse, J. Modern chlor-alkali technology, Vol. 8 (Wiley. com. 2008)

[12] S. Mahan, No excuses: communities at risk without mercury-free technology. Mercury 5.631, 2008, 1-12.

[13] A. K. Misra, Mercury pollution in and around a chlor-alkali industry: a review. Development 25, $2013,27$.

[14] T. F. O’Brien, T. F Bommaraju and Hine, F., Handbook of Chlor-Alkali Technology: Volume I: Fundamentals, (Springer, 2005)

[15] D. Bessarabov \& Z. Twardowski, New opportunities for osmotic membrane distillation. Membrane Technology 7, $2006,7-11$. 